\title{
PERBEDAAN TINGKAT KECEMASAN IBU BERSALIN PADA KELAS IBU HAMIL DI WILAYAH KERJA PUSKESMAS TULUNG
}

\author{
Intan Nugraheni, Kuswati \\ Kementerian Kesehatan Politeknik Kesehatan Surakarta Jurusan Kebidanan
}

\begin{abstract}
Class Pregnant Women; Levels Of Anxiety. Anxiety is one of the main factors that influence whether or not an action smoothness of delivery. Pregnant women with sufficient knowledge proved to have a low risk of the occurrence of complications of childbirth. Educational intervention in the form of counseling mothers on maternal class. Purpose is to knowing the differences in levels of maternal anxiety on the class of pregnant woman in the Puskesmas Tulung. Type of quasi-experimental research design with a static group comparison. The population is pregnant women PHC Tulung region. Samples are 36 pregnant women who meet the criteria cadre, which consisted of 18 pregnant women who attend classes pregnant women and 18 pregnant women who do not attend classes pregnant women with purposive sampling technique. Respondents who attend classes maternal anxiety has a value of at least 6 , the maximum value of 20 with an average of 15.4 and the majority of respondents (61.1\%) had anxiety medium category. Those who do not attend classes anxiety mother has a value of at least 14, the maximum value of 27, with an average of 20.67 and a majority of respondents have anxiety was (88.9\%). There are differences in the level of maternal anxiety that follows and that pregnant women do not attend classes in the Puskesmas Tulung, with significant differences in anxiety score ( $p$ value $=0.000$ ).
\end{abstract}

Keywords: Class Pregnant Women, Levels Of Anxiety

Abstrak : Kelas Ibu Hamil, Tingkat Kecemasan. Kecemasan merupakan salah satu faktor utama yang berpengaruh terhadap kelancaran atau tidaknya suatu tindakan persalinan. Ibu hamil dengan pengetahuan yang cukup terbukti mempunyai risiko yang rendah terhadap terjadinya komplikasi persalinan. Intervensi edukasi pada ibu dengan bentuk penyuluhan pada kelas ibu hamil. Mengetahui perbedaan tingkat kecemasan ibu bersalin pada terhadap kelas ibu hamil di wilayah kerja Puskesmas Tulung. Jenis penelitian eksperimen semu dengan desain static group comparison. Populasi yang digunakan adalah ibu hamil diwilayah Puskesmas Tulung. Sampel penelitian sebanyak $36 \mathrm{ibu}$ hamil kader yang memenuhi kriteria, yang terdiri dari $18 \mathrm{ibu}$ hamil yang mengikuti kelas ibu hamil dan 18 ibu hamil yang tidak mengikuti kelas ibu hamil dengan teknik purposive sampling. Responden yang mengikuti kelas ibu hamil mempunyai nilai kecemasan minimal 6, nilai maksimal 20 dengan rata-rata 15,4 dan sebagian besar responden $(61,1 \%)$ mempunyai kecemasan kategori sedang. Pada responden yang tidak mengikuti kelas ibu mempunyai nilai kecemasan minimal 14, nilai maksimal 27 dengan rata-rata 20,67 dan sebagian besar responden mempunyai kecemasan sedang $(88,9 \%)$. Ada perbedaan tingkat kecemasan ibu bersalin yang mengikuti dan yang tidak mengikuti kelas Ibu hamil di wilayah kerja Puskesmas Tulung, dengan nilai signifikan perbedaan kecemasan $(\mathrm{p}$ value $=0,000)$. 
Kata Kunci: Kelas Ibu Hamil, Tingkat Kecemasan

\section{PENDAHULUAN}

Kelancaran proses persalinan tidak hanya tergantung pada tenaga medis, tetapi juga dari ibu yang akan bersalin beserta anggota keluarganya. Persiapan persalinan yang direncanakan bersama bidan, diharapkan dapat menurunkan kebingungan dan kekacauan pada saat persalinan dan meningkatkan kemungkinan dimana ibu akan menerima asuhan yang sesuai serta tepat waktu (Depkes RI, 2002). Kebingungan merupakan bentuk dari kecemasan yang dirasakan oleh ibu.

Kecemasan merupakan salah satu faktor utama yang berpengaruh terhadap kelancaran atau tidaknya suatu tindakan persalinan. Ibu yang tidak tahu akan perubahan dirinya akan merasa cemas untuk menghadapi persalinan, sering kurang kooperatif untuk dilaksanakan tindakan medis selanjutnya. Penanganan tindakan medis yang tidak segera akan mengakibatkan pemberi pelayanan persalinan (bidan) mengambil keputusan untuk melaksanakan rujukan (Depkes RI, 2004).

Berdasarkan studi pendahuluan pada tahun 2013 kasus kala I dan kala II mendominasi kasus rujukan, yaitu sebanyak 15 (39\%) dari 64 kasus rujukan. Kala I dan kala II lama bisa jadi dipicu oleh kecemasan ibu yang berlebih sehingga kontraksi tidak teratur dan terjadi penurunan frekuensi dan durasi. Kecemasan dan ketakutan pada ibu dapat menimbulkan stress psikis dan justru akan melemahkan respon imunologi (daya tahan tubuh) dan mempersulit proses persalinan (Anwar, 2009).
Kelas ibu hamil merupakan sarana untuk belajar bersama tentang kesehatan bagi ibu hamil, dalam bentuk tatap muka dalam kelompok yang bertujuan meningkatkan pengetahuan dan ketrampilan ibu-ibu mengenai kehamilan, persalinan, perawatan nifas dan perawatan bayi baru lahir, mitos, penyakit menular dan akte kelahiran (Depkes RI dan JICA, 2008).

Intervensi edukasi pada ibu dengan bentuk penyuluhan pada kelas ibu hamil. Kelas ibu hamil adalah kelompok belajar ibu-ibu hamil dengan umur kehamilan antara 20 minggu s/d 32 minggu dengan jumlah peserta maksimal 10 orang. Di kelas ini ibu hamil akan belajar bersama, diskusi dan tukar pengalaman tentang kesehatan ibu dan anak secara menyeluruh dan sistematis serta dapat dilaksanakan secara terjadwal dan berkesinambungan (Depkes RI, 2009). Intervensi edukasi pada ibu hamil dengan cara penyuluhan terbukti mampu meningkatkan pengetahuan ibu hamil terhadap kehamilannya, dengan hasil akhir berupa rencana persalinan (Asysyakiry, 2003). Kelas ibu hamil dapat dilaksana-kan oleh lembaga pemerintah, swasta dan masyarakat. Di Puskesmas Tulung terdapat 10 kelompok kelas ibu hamil yang terdiri dari 112 orang. Adanya kelas ibu hamil diharapkan dapat mengurangi kecemasan yang dialami oleh ibu hamil, sehingga angka rujukan bisa ditekan. Dari 64 kasus rujukan, 3 diantaranya mengikuti kelas ibu hamil dengan kasus ibu hamil risiko tinggi karena faktor umur ibu lebih dari 35 tahun. Meskipun demikian, berdasarkan pengamatan peneliti, pasien dengan kasus tersebut tidak menunjukkan 
kecemasan dan menerima asuhan sebagaimana mestinya. Penelitian ini bertujuan untuk mengetahui perbedaan kecemasan ibu bersalin pada kelas ibu hamil di wilayah kerja Puskesmas Tulung.

\section{METODE PENELITIAN}

Jenis penelitian ini adalah eksperimen semu dengan rancangan static group comparison. Populasi dalam penelitian ini adalah semua ibu hamil di wilayah kerja Puskesmas Tulung yang aktif mengikuti kelas ibu hamil yaitu antara umur kehamilan 31 sampai 38 minggu. Sampel diambil dengan teknik purposive sampling. Analisis univariat digunakan untuk mendeskripsikan karakteritik masing-masing variabel yang diteliti, Perbedaan kecemasan ibu hamil diketahui independent sample t-test.

\section{HASIL PENELITIAN}

\section{Analisis Univariat}

\section{Tabel 1}

Distribusi Frekuensi Tingkat Kecemasan Responden Yang Mengikuti Kelas Ibu Hamil

\begin{tabular}{lcc}
\hline \multicolumn{1}{c}{ Kecemasan } & Frekuensi & Persentase \\
\hline $\begin{array}{l}\text { Tidak Ada } \\
\text { Kecemasan }\end{array}$ & 1 & 5,6 \\
\hline Cemas Ringan & 6 & 33,3 \\
\hline Cemas Sedang & 11 & 61,1 \\
\hline Cemas Berat & 0 & 0,0 \\
\hline Total & 18 & 100,0 \\
\hline
\end{tabular}

Berdasarkan Tabel 1 didapatkan sebagian besar responden yang mengikuti kelas ibu hamil pada kategori kecemasan sedang yaitu sebanyak 11 responden $(61,1 \%)$.

Tabel 2

Distribusi Frekuensi Tingkat Kecemasan Responden yang Tidak Mengikuti Kelas Ibu Hamil

\begin{tabular}{lcc}
\hline \multicolumn{1}{c}{ Kecemasan } & Frekuensi & Persentase \\
\hline Tidak Ada & 0 & 0,0 \\
Kecemasan & & \\
Cemas Ringan & 1 & 5,6 \\
Cemas Sedang & 16 & 88,9 \\
Cemas Berat & 1 & 5,6 \\
\hline Total & 18 & 100,0 \\
\hline
\end{tabular}

Berdasarkan Tabel 2 didapatkan sebagian besar responden yang tidak mengikuti kelas ibu hamil pada kategori kecemasan sedang yaitu sebanyak 16 responden $(88,9 \%)$.

\section{Analisis Bivariat}

Tabel 3

Perbedaan Tingkat Kecemasan Yang Mengikuti Kelas Ibu Hamil Dan Yang Tidak Mengikuti Kelas Ibu Hamil

\begin{tabular}{llrr}
\hline \multicolumn{2}{c}{ Kelompok } & Sig & T \\
\hline Cemas & Tidak & 0.000 & 3,997 \\
& Mengikuti & & \\
\cline { 2 - 4 } & Mengikuti & & \\
\hline
\end{tabular}

Berdasarkan Tabel 3 didapatkan uji statistik nilai $\mathrm{t}=3,997$ dengan $\mathrm{p}$ value sebesar 0,000 yang berarti bahwa ada perbedaan nilai kecemasan antara ibu yang mengikuti kelas ibu hamil dengan nilai ibu yang tidak mengikuti kelas ibu hamil.

\section{PEMBAHASAN}

Berdasarkan hasil penelitian kelas ibu hamil memberikan hasil yang signifikan terhadap penurunan kecemasan menghadapi persalinan. Dari hasil penelitian menunjukkan bahwa responden yang tidak mengikuti kelas ibu hamil mengalami kecemasan sedang yaitu sebesar $88,9 \%$, kecemasan ringan sebesar $5,6 \%$ dan kecemasan berat sebesar 5,6\%.

Kecemasan adalah ketergantungan, rasa tidak aman dan kekhawatiran yang timbul karena dirasakan terjadi sesuatu yang tidak menyenangkan tetapi sumbernya sebagian besar tidak diketahui 
dan berasal dari dalam diri individu (Depkes, RI, 2004.) Kecemasan merupakan salah satu faktor yang berpengaruh terhadap kelancaran suatu proses persalinan. Faktor - faktor yang mempengaruhi tingkat kecemasan antara lain : umur, status perkawinan, pendidikan dan pendapatan. Orang yang tingkat kecemasan tinggi akan memperlambat proses persalinan.

Menurut penelitihan yang pernah dilakukan Laksitoningrum dkk (2013) dengan judul perbedaan tingkat kecemasan dalam menghadapi persalinan pada ibu yang rutin dan yang tidak rutin melakukan kunjungan Antenatal care dengan hasil terdapat perbedaan tingkat kecemasan menghadapi persalinan antara ibu yang rutin dan yang tidak rutin melakukan kunjungan Antenatal care. Hasil penelitian adanya responden yang mengikuti kelas ibu hamil yang mengalami kecemasan sedang sebesar $61,1 \%$ sedangkan kecemasan ringan sebanyak 33,3\%.

Menurut Nursalam (2008) disamping usia, pendidikan, status perkawinan, pendapatan, maka kemampuan menangkap informasi mempengaruhi tingkat kecemasan seseorang. Semakin banyak informasi yang diterima, maka kecemasan semakin berkurang.

Kehamilan dapat merupakan sumber stresor kecemasan, terutama pada seorang ibu yang labil jiwanya. Kegelisahan dan kecemasan selama kehamilan merupakan kejadian yang tidak terelakkandan hampir selalu menyertai kehamilan. Selama masa kehamilan ibu hamil mengalami perubahan fisik dan psikologis yang dapat menimbulkan ketidaknyamanan terutama pada trimester III seperti dispnea, insomnia, gingivitis dan epulis, sering buang air kecil, tekanan dan ketidaknyamanan pada perineum, nyeri punggung, konstipasi, varises, mudah lelah, kontraksi Braxtonhicks, kram kaki, edema pergelangan kaki (non pitting) dan perubahan mood serta peningkatan kecemasan.

Oleh karena itu agar ibu hamil tidak mengalami kecemasan perlu mempersiapkan segala hal yang dapat membantu selama masa kehamilan dan saat proses melahirkan.

Keluhan kehamilan jika tidak tertangani akan mengarah kekomplikasi sehingga menimbulkan kekhawatiran dan kecemasan pada ibu. Wanita hamil primigravida hampir semuanya mengalami kekhawatiran, kecemasan, dan ketakutan baik selama hamil, saat menghadapi persalinan maupun setelah persalinan. Wanita hamil akan memiliki pikiran yang mengganggu sebagai pengembangan reaksi kecemasan terhadap cerita yang diperolehnya.

Kecemasan yang dirasakan umumnya berkisar pada takut perdarahan, takut bayinya cacat, takut terjadi komplikasi kehamilan, takut sakit saat melahirkan dan takut bila dijahitserta terjadi komplikasi pada saat persalinan, yang dapat menimbulkan kematian, hingga kekhawatiran jika kelak tidak bisa merawat dan membesarkan anak dengan baik. Tanpa disadari ketakutan proses melahirkan akantertanam pada pikiran bawah sadar dan akhirnya tertanam sebagai program negatif.

Peningkatan beban psikologis ibu dapat menimbulkan permasalahan terhadap kualitas janin yang dikandung dan komplikasi yang menyertai proses persalinan ibu. Beberapa penelitian menyebutkan bahwa tingkat depresi atau cemas selama trimester pertama kehamilan sama dengan kecemasan biasa 
pada umumnya sedangkan tingkat depresi selama trimester kedua dan ketiga hampir dua kali lipat trimester pertama.

Tujuan kelas ibu hamil adalah salah satunya meningkatkan pengetahuan, merubah sikap dan perilaku ibu agar memahami persalinan ,perawatan nifas, KB paska persalinan, perawatan bayi baru lahir, kepercayaan/adat istiadat setempat ( DepKes RI, 2009 ). Kelas ibu hamil dilaksanakan dalam tiga kali pertemuan. Pada pertemuan pertama materi yang diberikan adalah perubahan tubuh selama kehamilan.

Pada pertemuan ke dua dijelaskan mengenai persiapan persalinan dan perawatan nifas. Pada pertemuan ke dua ini materi tentang persiapan persalinan akan memberi gambaran kepada ibu tentang proses yang akan dialami sehingga ibu lebih siap dalam menghadapi proses bersalin dan mengurangi kecemasan. Pertemuan ke 3 (tiga) perawatan bayi, mitos, penyakit menular dan akte kelahiran. Pada setiap pertemuan dilakukan pretest dan postest, serta diakhiri dengan senam hamil.

Hasil penelitian Zamriati dkk (2013) dengan judul faktor-faktor yang berhubungan dengan kecemasan ibu hamil menjelang persalinan di Poli KIA PKM Tuminting dengan hasil ada hubungan yang signifikan antara umur, varitas dan pengalaman traumatis dengan tingkat kecemasan ibu sedangkan tingkat pendidikan tidak mempunyai hubungan yang signifikan dengan tingkat kecemasan ibu. Faktor-faktor yang bisa mengurangi kecemasan ibu yaitu dengan cara relaksasi atau istirahat, bantuan tenaga profesional, dan juga tingkat pendidikan.

Dari hasil penelitian didapatkan bahwa ibu hamil yang mengikuti kelas Antenatal mengalami kecemasan sedang yaitu $61,1 \%$ dan pada ibu yang tidak mengikuti kelas Antenatal mengalami kecemasan sedang sebanyak 88,9\%. Dari hasil uji bivariat didapatkan ada perbedaan tingkat kecemasan pada ibu bersalin yang mengikuti kelas ibu hamil dan yang tidak mengikuti kelas ibu hamil, dimana ibu yang mengikuti kelas ibu hamil nilai kecemasannya lebih rendah dibanding ibu yang tidak mengikuti kelas ibu hamil dengan nilai $\mathrm{T}$ sebesar 3,997 dan $p$ value sebesar 0,000 .

\section{KESIMPULAN DAN SARAN}

Ada perbedaan tingkat kecemasan ibu bersalin antara yang mengikuti kelas ibu hamil dan yang tidak mengikuti kelas ibu hamil. Tingkat kecemasan ibu bersalin yang mengikuti kelas ibu hamil di wilayah kerja Puskesmas Tulung sebagian besar pada kategori cemas sedang. Tingkat kecemasan ibu bersalin yang tidak mengikuti kelas ibu hamil di wilayah kerja Puskesmas Tulung sebagian besar pada kategori cemas sedang. Saran yang diberikan adalah diharapkan ibu hamil lebih aktif mengikuti kelas ibu hamil, sehingga pengetahuan yang diperoleh juga semakin bertambah sehingga mampu mengurangi kecemasan, dan mampu merencanakan persalinan dengan lebih baik. Puskesmas Diharapkan lebih intensif dalam mensosialiasikan kelas ibu hamil, dan memberikan motivasi kepada semua ibu hamil agar dapat mengikuti kelas ibu hamil.

\section{DAFTAR RUJUKAN}

Anwar, 2009. Konsep Kesehatan dalam Islam.http//www.keswais.com/inde x.php?M

Asysyakiry DA, 2003. Ante Natal Care dengan Pendekatan Integrated Management on Pregnancy And 
Childbirth (IMPAC) pada Ibu Hamil [skripsi]. Fakultas Kedokteran Universitas Diponegoro: Semarang.

Danuatmadja B, 2004. Persalinan Normal Tanpa Rasa Sakit, Cetakan I, Puspa

Depkes RI dan JICA. 2008. Kesehatan ibu dan anak. Jakarta.

Depkes RI, 2002. Standart Pelayanan Kebidanan. Jakarta.

Depkes RI, 2004. Komunikasi dengan Klien. Jakarta: Dirjen Yan Medik.

Depkes RI, 2006. Kurikulum Pelatihan Bagi Bidan Poskesdes Untuk Mewujudkan Desa Siaga. Jakarta

Depkes RI, 2009, Pedoman Pelaksanaan Kelas Ibu Hamil, Jakarta.

Firnawati, 2001. Hubungan Komunikasi Terapeutik dengan Tingkat Kecemasan Klien Dalam Berlangsung Persalinan. Yogyakarta : FK UGM.

Hawari, D. (2004). Manajemen Stress, Cemas dan Depresi. Jakarta: FK UI

Juwono, 2004. Persiapan menghadapi persalinan. Jakarta: Mitra Pustaka.

Mulyani, 2004. Efektifitas Komunikasi Teurapetik dengan Tingkat Kecemasan pada Pasien Pra Bedah Mayor di IRNA RSUP. Dr. Sardjito, FK UGM, Yogyakarta.

Mutmainah, Implementasi Program Desa Siaga di Kabupaten Klaten Tahun 2010, eprins.undip.ac.id/32628/1/mutmai nah.pdf

Notoatmodjo, S. 2005. Kesehatan masyarakat ilmu \& seni. Jakarta: PT. Rineka Cipta.

Notoatmodjo, S. 2007. Metodologi Penelitian Kesehatan. Jakarta: PT. Rineka Cipta
Sugiyono, 2005. Statistik Untuk Penelitian. Bandung: CV ALFABETA.

Suharsimi, 2006. Manajemen Penelitian. Jakarta: PT. Rineka Cipta 